\title{
Diagnostic value of contrast-enhanced ultrasound in hepatocellular carcinoma: a meta-analysis with evidence from 1998 to 2016
}

\author{
Juanjuan Zhang ${ }^{1, *}$, Yanyan $\mathbf{Y u}^{1,}{ }^{1}$, Ying Li ${ }^{1}$ and Lunshou Wei ${ }^{2}$ \\ ${ }^{1}$ Department of Ultrasound, Huaihe Hospital of Henan University, Kaifeng, China \\ ${ }^{2}$ Department of Gastroenterology, Huaihe Hospital of Henan University, Kaifeng, China \\ * Co-first authors
}

Correspondence to: Lunshou Wei, email: weilunshou@163.com

Keywords: hepatocellular carcinoma, contrast-enhanced ultrasound, diagnostic value, meta-analysis

Received: June 28, $2017 \quad$ Accepted: July 26, $2017 \quad$ Published: August 07, 2017

Copyright: Zhang et al. This is an open-access article distributed under the terms of the Creative Commons Attribution License 3.0 (CC BY 3.0), which permits unrestricted use, distribution, and reproduction in any medium, provided the original author and source are credited.

\section{ABSTRACT}

Background: This meta-analysis is aimed at determining the diagnostic value of hepatocellular carcinoma (HCC) with contrast-enhanced ultrasound (CEUS).

Materials and Methods: A comprehensive literature search of Pubmed, Web of Science, and the Cochrane Library was performed to identify published studies. The methodological quality of the included studies was evaluated. Data from eligible studies were used to estimate the pooled sensitivity, specificity, diagnostic odds ratio (DOR), positive and negative likelihood ratio (LR) and summary receiver operating characteristic (SROC) curve. Meta-Disc and STATA softwares were utilized for all statistical analyses.

Results: Fifty-three eligible studies (publication years ranged from 1998 to 2016) were selected according to inclusion criteria. The meta-analysis showed that the pooled sensitivity and specificity of CEUS to detect HCC were 0.85 (95\% CI: $0.84-$ $0.86)$ and 0.91 (95\% CI: $0.90-0.92)$, respectively. The pooled positive and negative LRs were 6.28 (95\% CI: 4.49-8.77) and 0.16 (95\% CI: 0.12-0.22), respectively. The pooled DOR was 55.01 (95\% CI: 35.25-83.47). The area under the SCOR curve was 0.9432. Meta-regression and funnel plot indicated that sample size, type of contrast agents and publication bias might be the major sources of heterogeneity.

Conclusions: CEUS is a valuable diagnostic tool for identifying HCC in clinic with highly sensitive and specific.

\section{INTRODUCTION}

According to the statistics, hepatocellular carcinoma (HCC) ranks the fifth most common cancer in men, the seventh in women [1]. An estimated 782,500 new liver cancer cases and 745,500 deaths occurred worldwide during 2012, with China alone accounting for about 50\% of the total number of cases and deaths [2]. Nowadays, HCC remains the life-threatening complaint despite the advanced surgical procedures and other nonoperative methods, with 5-year overall survival rate is less than $10 \%$ in its advanced stage [3]. Hence, early accurate diagnosis should be performed to improve patient's prognosis. Thanks to the typical hemodynamic changes of HCC (hypervascularity in the arterial phase followed by "washout" on portal or delayed phases), [4] the noninvasive diagnosis through imaging examinations could be reached without histologic confirmation.

However, currently established guidelines by the Association for the Study of Liver Diseases (AASLD), Liver Imaging Reporting and Data System (LI-RADS), and the Asian-Pacific Association for the Study of the Liver (APASL) all endorse multi-detector spiral CT and MRI with contrast agents as the first line modalities for diagnosing HCC [5-7], although ultrasound (US) is the more often used modality to monitoring the patients with hepatic cirrhosis who are at high risk for HCC in clinical practice [4]. In recent years, micro-bubble based contrast agents have greatly improved the sensitivity as well as specificity for characterization of focal liver 
lesions (FLLs) during the ultrasound examinations [8]. While, the role of contrast-enhanced ultrasound (CEUS) as a first line procedure for diagnosis of HCC still remains controversial. Some physicians are not convinced regarding the value of CEUS for the diagnosis of HCC. To this end, this systematic review and meta-analysis is conducted to evaluate the diagnostic value of CEUS in HCC.

\section{RESULTS}

\section{Identification of eligible studies}

A comprehensive literature search was conducted and revealed 3252 primary studies. Two studies were excluded due to duplicated publications. After reviewing the titles and abstracts, 2112 studies were excluded with the reasons as follows: (1) non-prospective / retrospective articles (meta-analyses, reviews, letters, case reports or editorial articles); (2) non-CEUS-related articles; (3) non-HCC related articles; (4) non-diagnostic tests. The remaining 238 articles were further assessed by screening the full texts, among which 185 articles were excluded due to (1) non-English published studies; (2) insufficient information; (3) not full text available; (4) sample size < 20; (5) repetitive study. Eventually, 53 eligible articles [9-61] were included in this meta-analysis. Detailed selection process was illustrated in a flow chart (Figure 1).

\section{Study characteristics and quality assessment}

The detailed characteristics of the 53 studies are presented in Supplementary Table 1. The average age of the patients included in the eligible studies ranged from 44 to 71 . And there were 5977 lesions in total, with more than 4827 patients (the numbers of patients were not mentioned in two studies). The publication years ranged from 1998 to 2016. There were 34 studies conducted in Asian population, and 19 studies conducted in European and American population. The second generation contrast agents for CEUS (SonoVue, Sonazoid and Definity) were used in 40 studies along with the first generation contrast agent (Levovist) in 13 studies. The methodological quality of the included 53 studies is also summarized in Supplementary Table 1.

\section{Diagnostic accuracy of HCC}

The pooled sensitivity and specificity of CEUS for the diagnosis of HCC were 0.85 (95\% CI: $0.84-0.86$ ) and 0.91 (95\% CI: $0.90-0.92)$, respectively (Figure 2). The pooled positive and negative LRs were 6.28 (95\% CI: 4.49 - 8.77) and 0.16 (95\% CI: $0.12-0.22)$, respectively. The pooled DOR was 55.01 (95\% CI: 35.25 - 83.47) (Figure 3). The meta-analysis results showed out that CEUS had high discriminatory powers of positive and negative test results. The SROC curve was illustrated in Figure 4. AUC of CEUS and the $\mathrm{Q}^{*}$ index were 0.9432 and 0.8816 , respectively, which were close to 1 . Thus, they indicated CEUS was a useful diagnostic tool to distinguish HCC from other liver lesions.

\section{Heterogeneity results}

As seen in the forest plots (Figure 2 and Figure 3), all indices of diagnostic accuracy denoted heterogeneity. Spearman correlation coefficient showed there was no significant correlation between sensitivity and specificity ( $r=0.060, P=0.669$ ), which indicated no threshold effect. To further explore the sources of heterogeneity, meta-

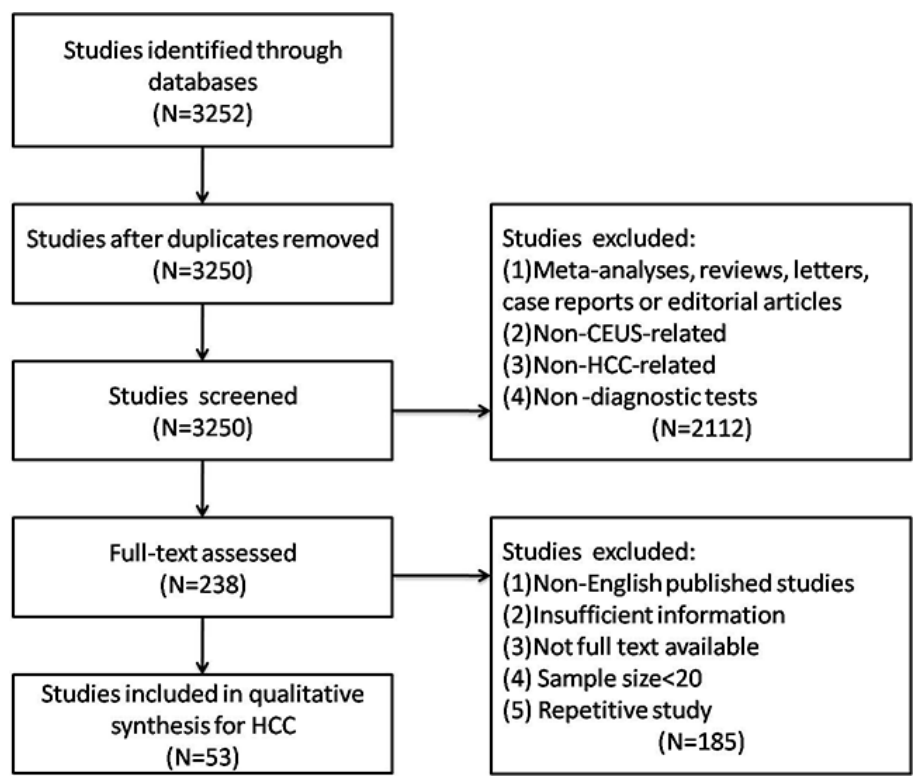

Figure 1: Flow chart of study selection. 
regression analysis was performed based on district (group1: Europe and America, group2: Asia), sample size (group 1: $n$ $<100$, group 2: $n \geq 100$ ) and type of contrast agents (group 1: SonoVue, group 2: Sonazoid, group 3: Definity, group 4: Levovist). The results indicated that sample size and type of contrast agents might be the major sources of heterogeneity ( $P=0.002, P=0.009$, respectively) (Table 1$)$.

Funnel plot was conducted to assess the publication bias of the eligible studies. However, as seen in Figure 5, the plot was asymmetric indicating that the publication bias existed $(P=0.000)$. This indicated publication bias might be another source of heterogeneity.

\section{DISCUSSION}

The utilization of microbubble-based ultrasound contrast agents along with the advanced US imaging techniques now allows stable observation and detailed evaluation of the tissue macro and microvascularization in both qualitative and quantitative manner [62]. According to other literatures, the ability of CEUS is similar to contrast-enhanced computed tomography (CECT) and contrast-enhanced resonance magnetic imaging (CEMRI) [63-64]. Beyond that, CEUS has unique advantages over CECT and CEMRI in the characterization of hepatic lesions. These include the capability of real-time dynamic imaging, repetitive observation of tumor vascularity with multiple injections of these contrast agents, and the unique

intravascular properties with excellent safety profile of the microbubbles, which allow the applications in patients with decreased renal function [8]. Although, the Food and Drug Administration (FDA) in U.S. finally approved their applications for a noncardia use in 2016, CEUS has been widely used for liver imaging especially for characterizing the HCCs in European and Asian countries for more than ten years [65]. This license might result in a possible breakthrough in the field of CEUS study.

The HCC multistep carcinogenesis (from regenerative nodule to dysplastic nodule, ending with HCC) leads to changes in blood supply within the nodule, which eventually forms increased tumoral arterial supply along with decreased normal arterial supply and portal supply as a consequent [66]. Thus, HCC is characterized by arterial phase hypervascularity followed by later and low washout on CEUS. Several researchers suggest that CEUS is superior to $\mathrm{CT}$ or MRI due to the real-time observation of arterial phase enhancement which might be missed by CT or MRI because of the predetermined scanning delay [67-68]. In our meta-analysis which performed on 53 eligible studies, the pooled sensitivity, specificity and DOR of CEUS for diagnosis of HCC were $0.85,0.91$ and 55.01, respectively. The pooled positive and negative LRs were 6.28 and 0.16 , respectively. All the results implied that CEUS might be the excellent choice in the diagnostic work-up of liver malignant lesions. Nevertheless,

A

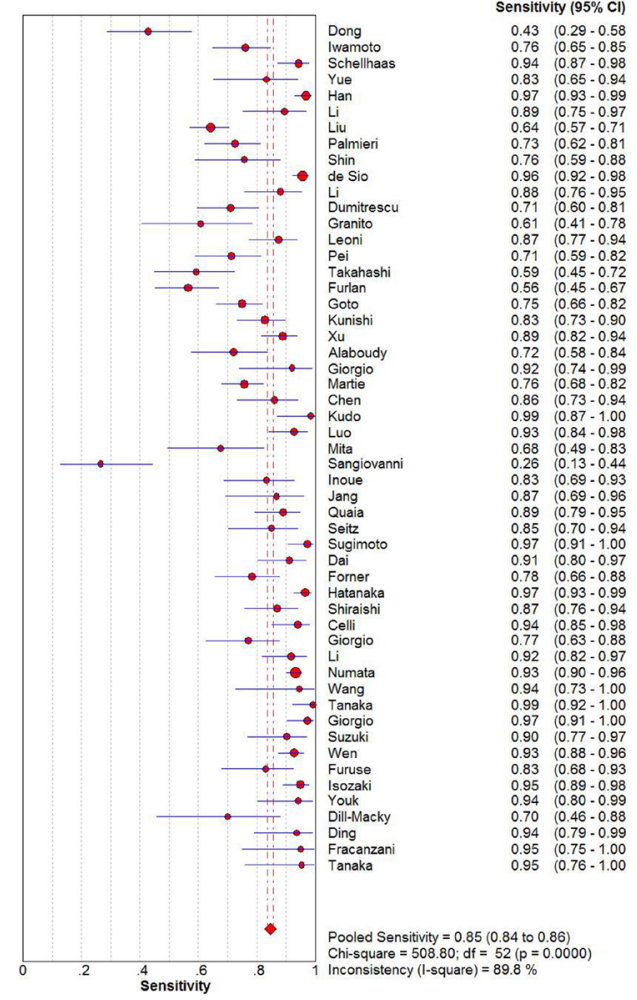

B

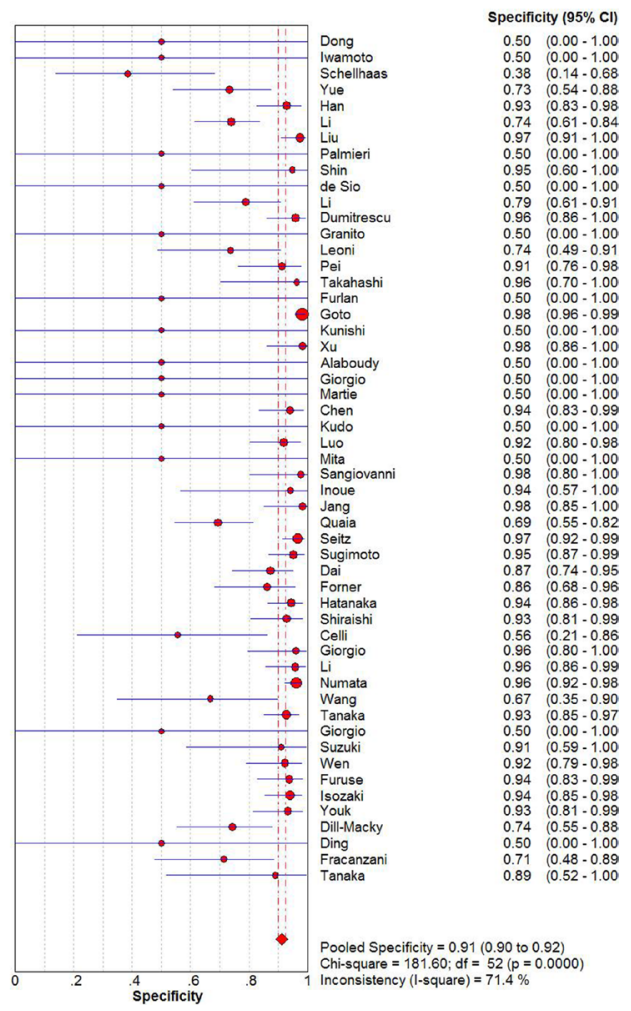

Figure 2: Sensitivity (A) and specificity (B) of diagnosis of HCC with CEUS. 
Table 1: Meta-regression analysis of potential source of heterogeneity

\begin{tabular}{ccccc}
\hline Potential sources & $\boldsymbol{P}$ value & RDOR & UL & LL \\
\hline District & 0.2515 & 1.56 & 0.72 & 3.37 \\
Sample size & 0.002 & 4.24 & 2.09 & 8.61 \\
Contrast agent & 0.009 & 1.93 & 1.33 & 2.80 \\
\hline
\end{tabular}

RDOR relative diagnostic odds ratio, UL upper limit, LL lower limit.

there still exist some disadvantages of CEUS. The main drawback is the operator-dependency in US examination. While our comprehensive meta-analysis showed good pooled diagnostic values with relatively narrow confidence intervals, indicating with certain skills and experience, most of the sonographers might achieve closely high diagnostic capability.
In our meta-analysis, great heterogeneity was revealed. While there was no explicit threshold effect in this meta-analysis, indicating that the threshold effect was not the source of heterogeneity. Therefore, metaregression analysis was performed to further explore the sources. And the results showed sample size and type of contrast agents might be the major sources of

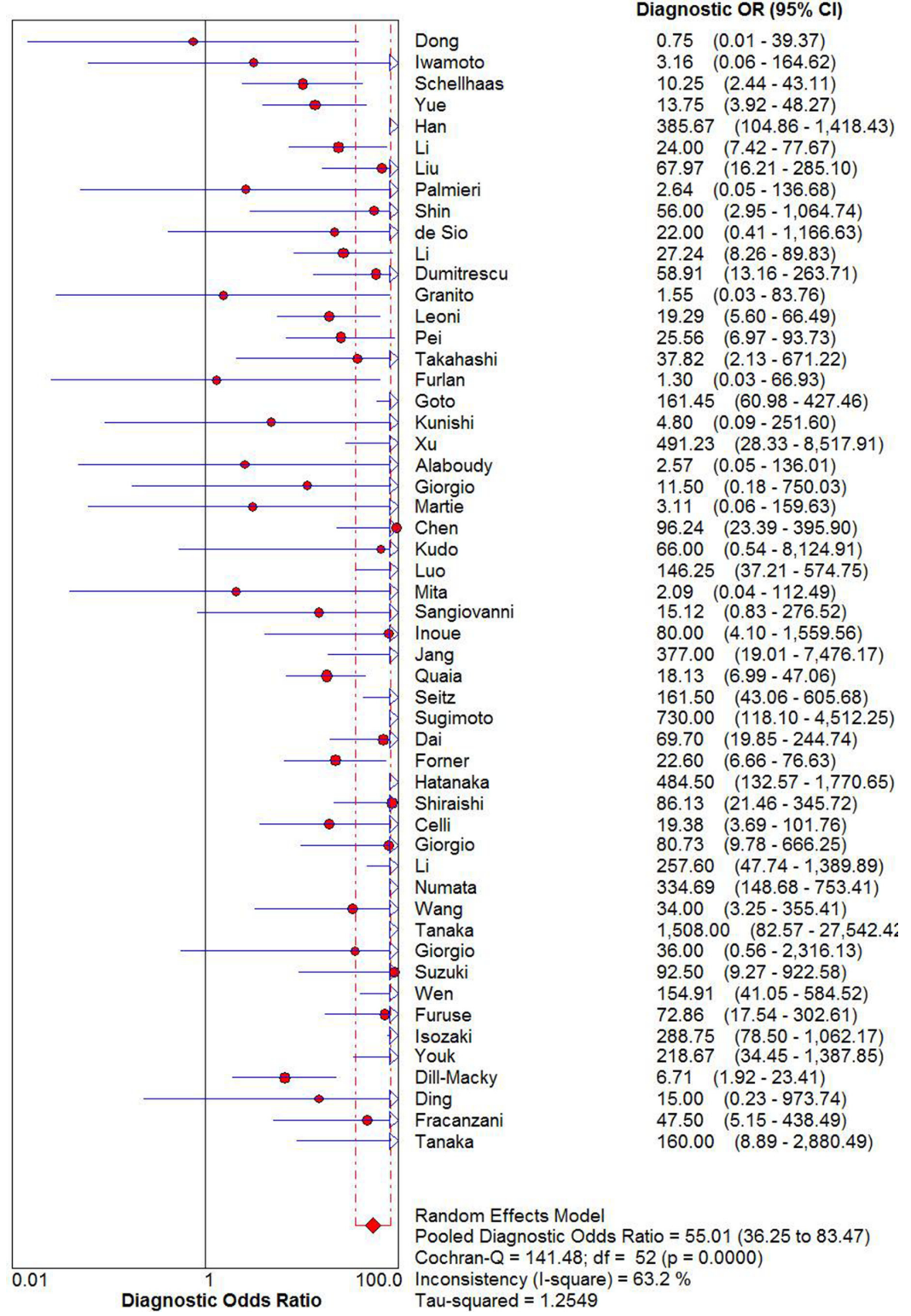

Figure 3: DOR of diagnosis of HCC with CEUS. 
heterogeneity. Publication bias was also detected in this meta-analysis, suggesting it might be another source of heterogeneity.

Moreover, some limitations in our meta-analysis should be acknowledged. Firstly, due to the publication bias explored in this meta-analysis, the pooled estimates might be more optimistic than they actually are, as studies with positive data are more likely to be published. Secondly, some studies indicated that the vascularity in small nodule could not be easily assessed by CEUS [69]. But since the data on small nodules couldn't be obtained in most of the eligible studies, the diagnostic value of CEUS for small HCC could not be estimated at present.

In conclusion, this comprehensive meta-analysis demonstrates the magnitude of the importance of CEUS in the diagnosis of HCC. Because of the advantages mentioned above, this approach would offer a major role in the diagnosis area, and additionally CEUS might become a first-line imaging tool in the future.

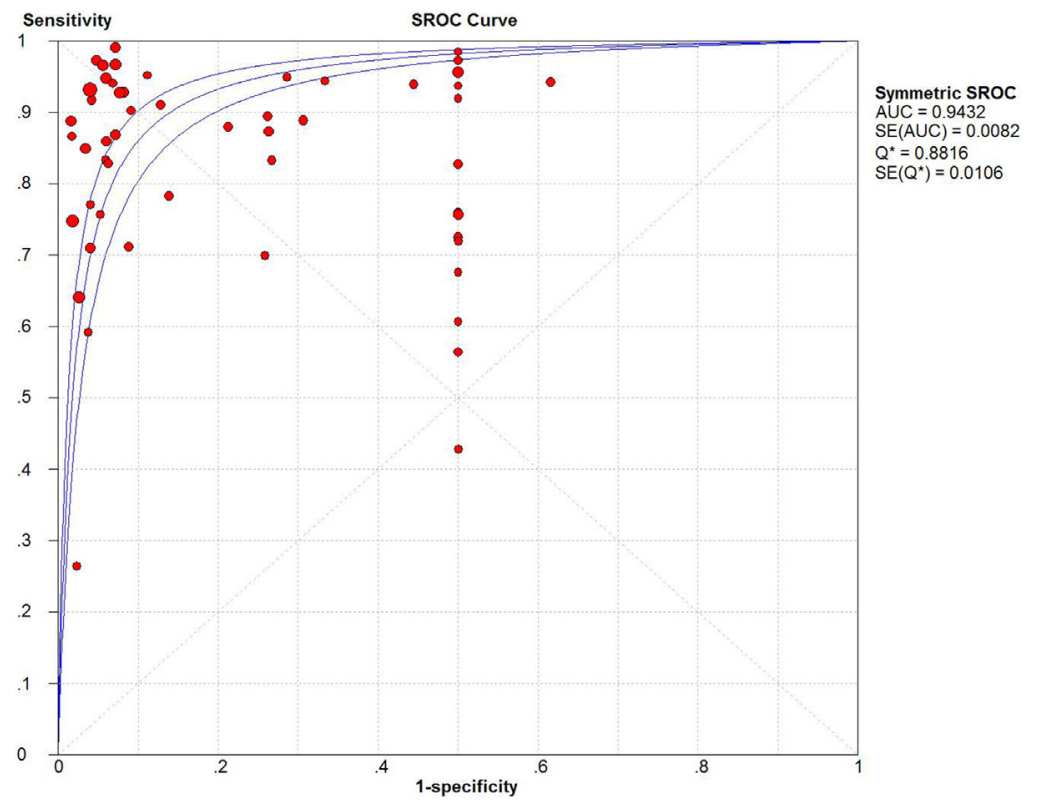

Figure 4: SROC curve of CEUS.

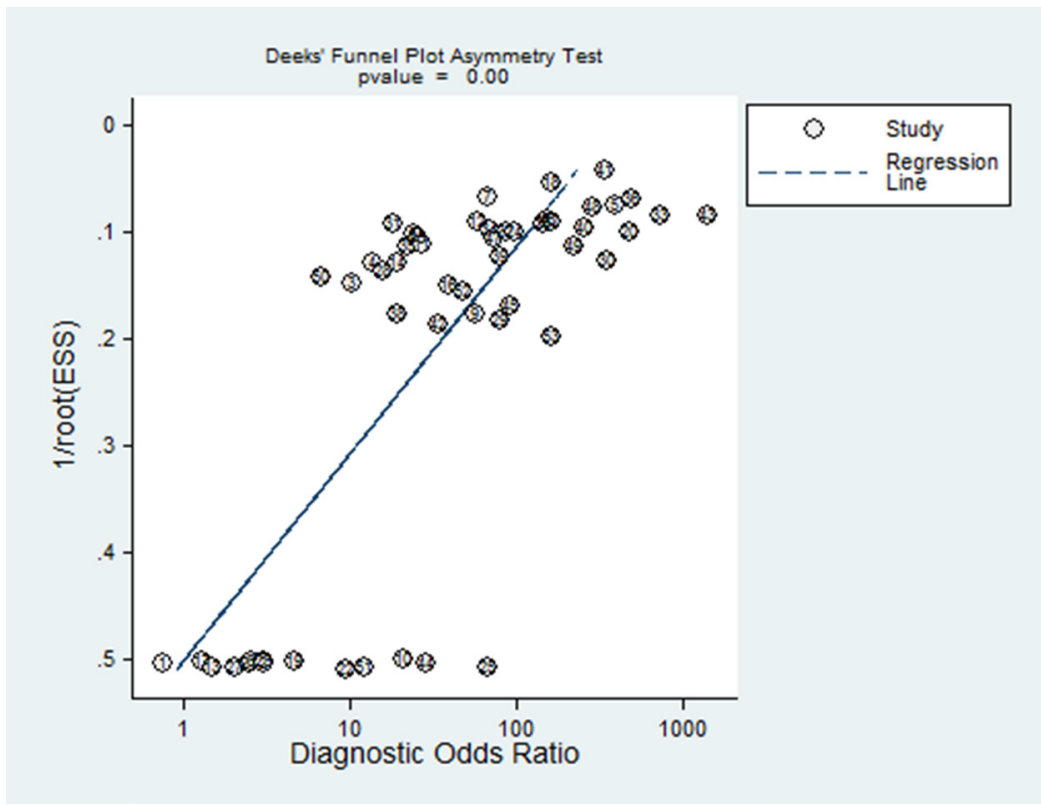

Figure 5: Funnel plot of publication bias on the pooled DOR. 


\section{MATERIALS AND METHODS}

\section{Literature search strategies}

A comprehensive literature search of studies was carried out to identify eligible articles from the electronic databases, including Pubmed, Web of Science, and the Cochrane Library, up to February 1st, 2017, and no limit to the starting time. The search terms included "hepatocellular carcinoma" OR "hepatic tumor" OR "liver tumor" OR "hepatic cancer" OR "liver cancer", AND "contrast-enhanced ultrasound" OR "contrastenhanced ultrasonography" OR "contrast-enhanced US" OR "CEUS" OR "contrast-enhanced Doppler ultrasonography". Additional relevant search was also performed by manually searching the references of eligible studies and relevant reviews.

\section{Study selection}

Two reviewers separately selected the eligible studies with disagreements disposed by consensus. Studies were considered eligible if they fulfilled the inclusion criteria: (1) full article published in English with the full text available; (2) articles dealing with the diagnosis of contrast-enhanced ultrasound for HCC; (3) articles confirmed the diagnosis with the reference standard as histopathologic analysis and/or close clinical diagnosis with imaging follow-up; (4) published data in the fourfold $(2 \times 2)$ tables or articles presented sufficient data to calculate the true-positive (TP), true-negative (TN), falsepositive (FP) and false-negative (FN); (5) at least 20 patients were included in the study. Studies were excluded when they were (1) meta-analyses, reviews, letters, case reports or editorial articles; (2) not clinical studies; (3) not using CEUS to diagnose HCC; (4) the patients were not confirmed the diagnosis with the above standards. If there existed more than one study by the same authors using the same cases published, either the most recently published studies or the study with the largest sample size was included.

\section{Data extraction}

All eligible studies were used for data extraction by two reviewers independently. Disagreements were disposed by a third reviewer. The following characteristics were extracted from the eligible studies: first author, publication year, country, number of lesions and patients, clinical characteristics of the study sample (age and gender ratio), gold standard, contrast agent, TP, TN, FP and FN.

\section{Quality assessment}

The methodological quality of eligible studies was assessed by the quality assessment tool for diagnostic accuracy studies (QUADAS). It contains fourteen assessment items, each of which was assessed as "yes" (1 score) or "no" (0 score) or "unclear" (-1 score).

\section{Statistical analysis}

Softwares of Meta-Disc (version 1.4, Universidad Complutense, Madrid, Spain) and STATA (version 11.0, STATA Corporation, College Station, Texas, USA) were used for all statistical analyses. For each study, we constructed $2 \times 2$ contingency tables wherein all subjects were classified to have positive or negative CEUS results. If one contingency table had a cell with no events, we added 0.5 to all cells. We calculated the sensitivity as TP/ $(\mathrm{TP}+\mathrm{FN})$, the specificity as $\mathrm{TN} /(\mathrm{TN}+\mathrm{FP})$, the positive likelihood ratio (PLR) as sensitivity/(1-specificity), the negative likelihood ratio (NLR) as (1-sensitivity)/ specificity, and the diagnostic odds ratio (DOR) as (TP $\times$ $\mathrm{TN}) /(\mathrm{FP} \times \mathrm{FN})$ along with their $95 \%$ confidence intervals (CIs). The summary receiver operating characteristic (SROC) curve, the area under the curve (AUC) as well as the $Q^{*}$ index were calculated. The threshold effect was tested by the Spearman correlation coefficient. The heterogeneity was assessed by Cochran's $Q$ statistic and $I^{2}$ test. When $I^{2} \geq 50 \%$ or $P_{\text {heterogeneity }}<0.05$, the random effect model was used in this meta-analysis, otherwise the fixed effect model was used. Potential sources of heterogeneity were explored by regression analysis. The potential publication bias was assessed by the funnel plot. $P$ values were two-sided and difference was considered as statistically significant when $P<0.05$.

\section{Abbreviations}

Hepatocellular carcinoma $=$ HCC, contrastenhanced ultrasound $=$ CEUS, Association for the Study of Liver Diseases $=$ AASLD, Liver Imaging Reporting and Data System = LI-RADS, Asian-Pacific Association for the Study of the Liver = APASL, ultrasound $=$ US, focal liver lesions $=$ FLLs, true-positive $=\mathrm{TP}$, truenegative $=\mathrm{TN}$, false-positive $=\mathrm{FP}$, false-negative $=\mathrm{FN}$, quality assessment tool for diagnostic accuracy studies $=$ QUADAS, positive likelihood ratio $=$ PLR, negative likelihood ratio $=$ NLR, diagnostic odds ratio $=$ DOR, confidence intervals $=\mathrm{CIs}$, summary receiver operating characteristic $=$ SROC, area under the curve $=$ AUC.

\section{ACKNOWLEDGMENTS}

Lunshou Wei conceived and designed the overall study. Juanjuan Zhang and Yanyan Yu contributed to the reference collection and data management. Ying Li performed the analysis. Juanjuan Zhang and Yanyan $\mathrm{Yu}$ wrote the manuscript. All authors contributed to the preparation of the manuscript and approved the final version. 


\section{CONFLICTS OF INTEREST}

There are no conflicts of interest.

\section{REFERENCES}

1. Bosetti C, Turati F, La VC. Hepatocellular carcinoma epidemiology. Best Pract Res Clin Gastroenterol. 2014; 28:753-70.

2. Torre LA, Bray F, Siegel RL, Ferlay J, Lortet-Tieulent J, Jemal A. Global cancer statistics, 2012. CA Cancer J Clin. $2015 ; 65: 87-108$

3. Trevisani F, Cantarini MC, Wands JR, Bernardi M. Recent advances in the natural history of hepatocellular carcinoma. Carcinogenesis. 2008; 29:1299-305.

4. Yoon JH, Park JW, Lee JM. Noninvasive diagnosis of hepatocellular carcinoma: elaboration on Korean liver cancer study group-national cancer center korea practice guidelines compared with other guidelines and remaining Issues. Korean J Radiol. 2016; 17:7-24.

5. Bruix J, Sherman M, American Association for the Study of Liver Diseases. Management of hepatocellular carcinoma: an update. Hepatology. 2011; 53:1020-2.

6. An C, Rakhmonova G, Choi JY, Kim MJ. Liver imaging reporting and data system (LI-RADS) version 2014: understanding and application of the diagnostic algorithm. Clin Mol Hepatol. 2016; 22:296-307.

7. Omata M, Kanda T, Yu ML, Yokosuka O, Lim SG, Jafri W, Tateishi R, Hamid SS, Chuang WL, Chutaputti A, Wei L, Sollano J, Sarin SK, et al. APASL consensus statements and management algorithms for hepatitis $\mathrm{C}$ virus infection. Hepatol Int. 2012; 6:409-35.

8. Salvatore V, Borghi A, Piscaglia F. Contrast-enhanced ultrasound for liver imaging: recent advances. Current Pharmaceutical Design. 2012; 18:2236-52.

9. Dong Y, Wang WP, Mao F, Ji ZB, Huang BJ. Application of imaging fusion combining contrast-enhanced ultrasound and magnetic resonance imaging in characterization of hepatic cellular carcinomas undetectable by conventional ultrasound. J Gastroenterol Hepatol. 2016; 31:822-8.

10. Iwamoto $\mathrm{T}$, Imai $\mathrm{Y}$, Kogita $\mathrm{S}$, Igura $\mathrm{T}$, Sawai $\mathrm{Y}$, Fukuda K, Yamaguchi Y, Matsumoto Y, Nakahara M, Morimoto O, Seki Y, Ohashi H, Fujita N, et al. Comparison of contrast-enhanced ultrasound and gadoliniumethoxybenzyl-diethylenetriamine pentaacetic acid-enhanced MRI for the diagnosis of macroscopic type of hepatocellular carcinoma. Dig Dis. 2016; 34:679-86.

11. Schellhaas B, Wildner D, Pfeifer L, Goertz RS, Hagel A, Neurath MF, Strobel D. LI-RADS-CEUS-Proposal for a contrast-enhanced ultrasound algorithm for the diagnosis of hepatocellular carcinoma in high-risk populations. Ultraschall Med. 2016; 37:627-34.

12. Yue WW, Wang S, Xu HX, Sun LP, Guo LH, Bo XW, Li XL, Zhao CK, Wang D, Liu BJ. Parametric imaging with contrast-enhanced ultrasound for differentiating hepatocellular carcinoma from metastatic liver cancer. Clin Hemorheol Microcirc. 2016; 64:177-88.

13. Han J, Liu Y, Han F, Li Q, Yan C, Zheng W, Wang J, Guo Z, Wang J, Li A, Zhou J. The degree of contrast washout on contrast-enhanced ultrasound in distinguishing intrahepatic cholangiocarcinoma from hepatocellular carcinoma. Ultrasound Med Biol. 2015; 41:3088-95.

14. Li W, Wang W, Liu GJ, Chen LD, Wang Z, Huang Y, Liu JY, Xie XY, Lu MD. Differentiation of atypical hepatocellular carcinoma from focal nodular hyperplasia: diagnostic performance of contrast-enhanced US and microflow imaging. Radiology. 2015; 275:870-9.

15. Liu GJ, Wang W, Lu MD, Xie XY, Xu HX, Xu ZF, Chen LD, Wang Z, Liang JY, Huang Y, Li W, Liu JY. Contrast-enhanced ultrasound for the characterization of hepatocellular carcinoma and intrahepatic cholangiocarcinoma. Liver Cancer. 2015; 4:241-52.

16. Palmieri VO, Santovito D, Marano G, Minerva F, Ricci L, D'Alitto F, Angelelli G, Palasciano G. Contrast-enhanced ultrasound in the diagnosis of hepatocellular carcinoma. Radiol Med. 2015; 120:627-33.

17. Shin SK, Kim YS, Choi SJ, Shim YS, Jung DH, Kwon OS, Choi DJ, Kim JH. Contrast-enhanced ultrasound for the differentiation of small atypical hepatocellular carcinomas from dysplastic nodules in cirrhosis. Dig Liver Dis. 2015; 47:775-82.

18. de Sio I, Iadevaia MD, Vitale LM, Niosi M, Del Prete A, de Sio C, Romano L, Funaro A, Meucci R, Federico A, Loguercio C, Romano M. Optimized contrast-enhanced ultrasonography for characterization of focal liver lesions in cirrhosis: A single-center retrospective study. United European Gastroenterol J. 2014; 2:279-87.

19. Li R, Yuan MX, Ma KS, Li XW, Tang CL, Zhang XH, Guo DY, Yan XC. Detailed analysis of temporal features on contrast enhanced ultrasound may help differentiate intrahepatic cholangiocarcinoma from hepatocellular carcinoma in cirrhosis. PLoS One. 2014; 9:e98612.

20. Dumitrescu CI, Gheonea IA, Săndulescu L, Surlin V, Săftoiu A, Dumitrescu D. Contrast enhanced ultrasound and magnetic resonance imaging in hepatocellular carcinoma diagnosis. Med Ultrason. 2013; 15:261-7.

21. Granito A, Galassi M, Piscaglia F, Romanini L, Lucidi V, Renzulli M, Borghi A, Grazioli L, Golfieri R, Bolondi L. Impact of gadoxetic acid (Gd-EOB-DTPA)-enhanced magnetic resonance on the non-invasive diagnosis of small hepatocellular carcinoma: a prospective study. Aliment Pharmacol Ther. 2013; 37:355-63.

22. Leoni S, Piscaglia F, Granito A, Borghi A, Galassi M, Marinelli S, Terzi E, Bolondi L. Characterization of primary and recurrent nodules in liver cirrhosis using contrastenhanced ultrasound: which vascular criteria should be adopted? Ultraschall Med. 2013; 34:280-7.

23. Pei XQ, Liu LZ, Xiong YH, Zou RH, Chen MS, Li AH, Cai MY. Quantitative analysis of contrast-enhanced 
ultrasonography: differentiating focal nodular hyperplasia from hepatocellular carcinoma. Br J Radiol. 2013; 86:20120536.

24. Takahashi M, Maruyama H, Shimada T, Kamezaki H, Sekimoto T, Kanai F, Yokosuka O. Characterization of hepatic lesions $(\leq 30 \mathrm{~mm})$ with liver-specific contrast agents: a comparison between ultrasound and magnetic resonance imaging. Eur J Radiol. 2013; 82:75-84.

25. Furlan A, Marin D, Cabassa P, Taibbi A, Brunelli E, Agnello F, Lagalla R, Brancatelli G. Enhancement pattern of small hepatocellular carcinoma (HCC) at contrast-enhanced US (CEUS), MDCT, and MRI: intermodality agreement and comparison of diagnostic sensitivity between 2005 and 2010 American Association for the Study of Liver Diseases (AASLD) guidelines. Eur J Radiol. 2012; 81:2099-105.

26. Goto E, Masuzaki R, Tateishi R, Kondo Y, Imamura J, Goto $\mathrm{T}$, Ikeda $\mathrm{H}$, Akahane M, Shiina S, Omata M, Yoshida H, Koike K. Value of post-vascular phase (Kupffer imaging) by contrast-enhanced ultrasonography using Sonazoid in the detection of hepatocellular carcinoma. J Gastroenterol. 2012; 47:477-85.

27. Kunishi Y, Numata K, Morimoto M, Okada M, Kaneko T, Maeda S, Tanaka K. Efficacy of fusion imaging combining sonography and hepatobiliary phase MRI with Gd-EOBDTPA to detect small hepatocellular carcinoma. AJR Am J Roentgenol. 2012; 198:106-14.

28. Xu HX, Lu MD, Liu LN, Zhang YF, Guo LH, Xu JM, Liu C. Discrimination between neoplastic and nonneoplastic lesions in cirrhotic liver using contrast-enhanced ultrasound. Br J Radiol. 2012; 85:1376-84.

29. Alaboudy A, Inoue T, Hatanaka K, Chung H, Hyodo T, Kumano S, Murakami T, Moustafa EF, Kudo M. Usefulness of combination of imaging modalities in the diagnosis of hepatocellular carcinoma using Sonazoid®-enhanced ultrasound, gadolinium diethylene-triamine-pentaacetic acid-enhanced magnetic resonance imaging, and contrastenhanced computed tomography. Oncology. 2011; 81:66-72.

30. Giorgio A, Calisti G, di Sarno A, Farella N, de Stefano G, Scognamiglio U, Giorgio V. Characterization of dysplastic nodules, early hepatocellular carcinoma and progressed hepatocellular carcinoma in cirrhosis with contrastenhanced ultrasound. Anticancer Res. 2011; 31:3977-82.

31. Martie A, Sporea I, Popescu A, Sirli R, Dănilă M, Serban C, Ardelean M, Bota S, Sendroiu M, Chisevescu D. Contrast enhanced ultrasound for the characterization of hepatocellular carcinoma. Med Ultrason. 2011; 13:108-13.

32. Chen LD, Xu HX, Xie XY, Xie XH, Xu ZF, Liu GJ, Wang $\mathrm{Z}$, Lin MX, Lu MD. Intrahepatic cholangiocarcinoma and hepatocellular carcinoma: differential diagnosis with contrast-enhanced ultrasound. Eur Radiol. 2010; 20:743-53.

33. Kudo M, Hatanaka K, Maekawa K. Newly developed novel ultrasound technique, defect reperfusion ultrasound imaging, using sonazoid in the management of hepatocellular carcinoma. Oncology. 2010; 78:40-5.
34. Luo W, Numata K, Morimoto M, Nozaki A, Ueda M, Kondo M, Morita S, Tanaka K. Differentiation of focal liver lesions using three-dimensional ultrasonography: retrospective and prospective studies. World J Gastroenterol. 2010; 16:2109-19.

35. Mita K, Kim SR, Kudo M, Imoto S, Nakajima T, Ando K, Fukuda K, Matsuoka T, Maekawa Y, Hayashi Y. Diagnostic sensitivity of imaging modalities for hepatocellular carcinoma smaller than $2 \mathrm{~cm}$. World J Gastroenterol. 2010; 16:4187-92.

36. Sangiovanni A, Manini MA, Iavarone $M$, Romeo R, Forzenigo LV, Fraquelli M, Massironi S, Della Corte C, Ronchi G, Rumi MG, Biondetti P, Colombo M. The diagnostic and economic impact of contrast imaging techniques in the diagnosis of small hepatocellular carcinoma in cirrhosis. Gut. 2010; 59:638-44.

37. Inoue T, Kudo M, Maenishi O, Komuta M, Nakashima O, Kojiro M, Maekawa K. Value of liver parenchymal phase contrast-enhanced sonography to diagnose premalignant and borderline lesions and overt hepatocellular carcinoma. AJR Am J Roentgenol. 2009; 192:698-705.

38. Jang HJ, Kim TK, Wilson SR. Small nodules $(1-2 \mathrm{~cm})$ in liver cirrhosis: characterization with contrast-enhanced ultrasound. Eur J Radiol. 2009; 72:418-24.

39. Quaia E, Alaimo V, Baratella E, Medeot A, MidiriM, Cova MA. The added diagnostic value of 64-row multidetector CT combined with contrast-enhanced US in the evaluation of hepatocellular nodule vascularity: implications in the diagnosis of malignancy in patients with liver cirrhosis. Eur Radiol. 2009; 19:651-63.

40. Seitz K, Strobel D, Bernatik T, Blank W, FriedrichRust M, Herbay Av, Dietrich CF, Strunk H, Kratzer W, Schuler A. Contrast-Enhanced Ultrasound (CEUS) for the characterization of focal liver lesions - prospective comparison in clinical practice: CEUS vs. CT (DEGUM multicenter trial). Ultraschall Med. 2009; 30:383-89.

41. Sugimoto K, Shiraishi J, Moriyasu F, Doi K. Computeraided diagnosis of focal liver lesions by use of physicians> subjective classification of echogenic patterns in baseline and contrast-enhanced ultrasonography. Acad Radiol. 2009; 16:401-11.

42. Dai Y, Chen MH, Fan ZH, Yan K, Yin SS, Zhang XP. Diagnosis of small hepatic nodules detected by surveillance ultrasound in patients with cirrhosis: comparison between contrast-enhanced ultrasound and contrast-enhanced helical computed tomography. Hepatol Res. 2008; 38:281-90.

43. Forner A, Vilana R, Ayuso C, Bianchi L, Solé M, Ayuso JR, Boix L, Sala M, Varela M, Llovet JM, Brú C, Bruix J. Diagnosis of hepatic nodules $20 \mathrm{~mm}$ or smaller in cirrhosis: Prospective validation of the noninvasive diagnostic criteria for hepatocellular carcinoma. Hepatology. 2008; 47:97-104.

44. Hatanaka K, Kudo M, Minami Y, Ueda T, Tatsumi C, Kitai S, Takahashi S, Inoue T, Hagiwara S, Chung H, Ueshima K, Maekawa K. Differential diagnosis of hepatic 
tumors: value of contrast-enhanced harmonic sonography using the newly developed contrast agent, Sonazoid. Intervirology. 2008; 51:61-9.

45. Shiraishi J, Sugimoto K, Moriyasu F, Kamiyama N, Doi K. Computer-aided diagnosis for the classification of focal liver lesions by use of contrast-enhanced ultrasonography. Med Phys. 2008; 35:1734-46.

46. Celli N, Gaiani S, Piscaglia F, Zironi G, Camaggi V, Leoni S, Righini R, Bolondi L. Characterization of liver lesions by real-time contrast-enhanced ultrasonography. Eur J Gastroenterol Hepatol. 2007; 19:3-14.

47. Giorgio A, De Stefano G, Coppola C, Ferraioli G, Esposito V, Di Sarno A, Giorgio V, De Stefano M, Sangiovanni V, Liorre G, Del Viscovo L. Contrast-enhanced sonography in the characterization of small hepatocellular carcinomas in cirrhotic patients: comparison with contrast-enhanced ultrafast magnetic resonance imaging. Anticancer Res. 2007; 27:4263-9.

48. Li R, Guo Y, Hua X, He Y, Ding J, Guo A, Luo M. Characterization of focal liver lesions: comparison of pulseinversion harmonic contrast-enhanced sonography with contrast-enhanced CT. J Clin Ultrasound. 2007; 35:109-17.

49. Numata $K$, Isozaki $T$, Morimoto $M$, Sugimori $K$, Kunisaki R, Morizane T, Tanaka K. Prospective study of differential diagnosis of hepatic tumors by pattern-based classification of contrast-enhanced sonography. World J Gastroenterol. 2006; 12:6290-8.

50. Wang JH, Lu SN, Hung $\mathrm{CH}$, Chen TY, Chen $\mathrm{CH}$, Changchien CS, Lee CM. Small hepatic nodules $(<$ or $=2$ $\mathrm{cm})$ in cirrhosis patients: characterization with contrastenhanced ultrasonography. Liver Int. 2006; 26:928-34.

51. Tanaka S, Hamada Y, Ioka T, Sugiyama T, Akamatsu I, Takakura R, Yoshioka F, Nakaizumi A, Ishida T. Contrastenhanced multiphase dynamic ultrasonography for the characterization of liver tumors. J Med Ultrason. 2005; 32:57-63.

52. Giorgio A, Ferraioli G, Tarantino L, de Stefano G, Scala V, Scarano F, Coppola C, Del Viscovo L. Contrast-enhanced sonographic appearance of hepatocellular carcinoma in patients with cirrhosis: comparison with contrast-enhanced helical CT appearance. AJR Am J Roentgenol. 2004; 183:1319-26.

53. Suzuki S, Iijima H, Moriyasu F, Sasaki S, Yanagisawa K, Miyahara T, Oguma K, Yoshida M, Horibe T, Ito N, Kakizaki D, Abe K, Tsuchiya K. Differential diagnosis of hepatic nodules using delayed parenchymal phase imaging of levovist contrast ultrasound: comparative study with SPIO-MRI. Hepatol Res. 2004; 29:122-6.

54. Wen YL, Kudo M, Zheng RQ, Ding H, Zhou P, Minami Y, Chung H, Kitano M, Kawasaki T, Maekawa K. Characterization of hepatic tumors: value of contrastenhanced coded phase-inversion harmonic angio. AJR Am J Roentgenol. 2004; 182:1019-26.

55. Furuse J, Nagase M, Ishii H, Yoshino M. Contrast enhancement patterns of hepatic tumours during the vascular phase using coded harmonic imaging and Levovist to differentiate hepatocellular carcinoma from other focal lesions. Br J Radiol. 2003; 76:385-92.
56. Isozaki $T$, Numata $K$, Kiba $T$, Hara $K$, Morimoto $M$, Sakaguchi T, Sekihara H, Kubota T, Shimada H, Morizane T, Tanaka K. Differential diagnosis of hepatic tumors by using contrast enhancement patterns at US. Radiology. 2003; 229:798-805.

57. Youk JH, Kim CS, Lee JM. Contrast-enhanced agent detection imaging: value in the characterization of focal hepatic lesions. J Ultrasound Med. 2003; 22:897-910.

58. Dill-Macky MJ, Burns PN, Khalili K, Wilson SR. Focal hepatic masses: enhancement patterns with SH U 508A and pulse-inversion US. Radiology. 2002; 222:95-102.

59. Ding H, Kudo M, Onda H, Suetomi Y, Minami Y, Maekawa K. Contrast-enhanced subtraction harmonic sonography for evaluating treatment response in patients with hepatocellular carcinoma. AJR Am J Roentgenol. 2001; 176:661-6.

60. Fracanzani AL, Burdick L, Borzio M, Roncalli M, Bonelli N, Borzio F, Maraschi A, Fiorelli G, Fargion S. Contrast-enhanced Doppler ultrasonography in the diagnosis of hepatocellular carcinoma and premalignant lesions in patients with cirrhosis. Hepatology. 2001; 34:1109-12.

61. Tanaka S, Kitamra T, Fujita M, Yoshioka F. Value of contrast-enhanced color Doppler sonography in diagnosing hepatocellular carcinoma with special attention to the "color-filled pattern". J Clin Ultrasound. 1998; 26:207-12.

62. Maruyama H, Sekimoto T, Yokosuka O. Role of contrastenhanced ultrasonography with Sonazoid for hepatocellular carcinoma: evidence from a 10-year experience. J Gastroenterol. 2016; 51:421-33.

63. Xie L, Guang Y, Ding H, Cai A, Huang Y. Diagnostic value of contrast-enhanced ultrasound, computed tomography and magnetic resonance imaging for focal liver lesions: a metaanalysis. Ultrasound Med Biol. 2011; 37:854-861.

64. Zheng SG, Xu HX, Liu LN. Management of hepatocellular carcinoma: The role of contrast-enhanced ultrasound. World J Radiol. 2014; 6:7-14.

65. Seitz K, Strobel D. A Milestone: Approval of CEUS for Diagnostic Liver Imaging in Adults and Children in the USA. Ultraschall Med. 2016; 37:229-32.

66. Kudo M. Multistep human hepatocarcinogenesis: correlation of imaging with pathology. J Gastroenterol. 2009; 44:112-8.

67. Kudo M, Matsui O, Izumi N, Iijima H, Kadoya M, Imai Y, Liver Cancer Study Group of Japan. Surveillance and diagnostic algorithm for hepatocellular carcinoma proposed by the Liver Cancer Study Group of Japan: 2014 update. Oncology. 2014; 87:7-21.

68. Jang HJ, Yu H, Kim TK. Contrast-enhanced ultrasound in the detection and characterization of liver tumors. Cancer Imaging. 2009; 9:96-103.

69. Leoni S, Piscaglia F, Golfieri R, Camaggi V, Vidili G, Pini P, Bolondi L. The impact of vascular and nonvascular findings on the noninvasive diagnosis of small hepatocellular carcinoma based on the EASL and AASLD criteria. Am J Gastroenterol. 2010; 105:599-609. 